\title{
Characterisation of Platinum Nanoparticles Electrodeposited on Carbon Felt
}

\author{
S. M. S. I. Dulal ${ }^{1 *}$, Mi-Sook Won ${ }^{2}$, and Yoon-Bo Shim ${ }^{3 *}$ \\ ${ }^{1}$ Department of Materials Science and Engineering, University of Rajshahi, Rajshahi 6205, \\ Bangladesh \\ ${ }^{2}$ Busan Center, Korea Basic Science Institute, Busan 609-735, South Korea \\ ${ }^{3}$ Department of Chemistry, Pusan National University, Busan 609-735, South Korea
}

Received 29 October 2009, accepted in revised form 13 February 2010

\begin{abstract}
Monodispersed and uniform sized platinum nanoparticles were electrodeposited on carbon felt from aqueous hydrogen hexachloroplatinate solution by a potential cycling method. The deposited nanoparticles were characterized by electrochemical technique and by scanning electron microscopy. It was found that the size and distribution of the nanoparticles could be controlled by changing the deposition parameters such as the scan rate and the number of cycle. The electrocatalytic property of the nanoparticles was tested by the oxidation of hydroquinone and phenol. It was found that the felt supported nanoparticles were effective towards electrodegradation of phenolic compounds.
\end{abstract}

Keywords: Electrocatalyst; Electrodeposition; Hydroquinone; Phenol oxidation; Platinum nanoparticles; Carbon felt.

(C) 2010 JSR Publications. ISSN: 2070-0237 (Print); 2070-0245 (Online). All rights reserved.

DOI: 10.3329/jsr.v2i2.3633 J. Sci. Res. 2 (2), 303-312 (2010)

\section{Introduction}

There is much research interest in carbon supported platinum nanoparticles for their use as electrode materials in electrochemical catalysis and sensing [1-19]. A very important step in designing a structurally and dimensionally stable nanoparticle based electrode is the incorporation of electrocatalytically active nanoparticles onto a suitable support. This can be accomplished by pasting chemically synthesized nanoparticles on the catalyst support or by electrodepositing the nanoparticles on the support. Direct electrochemical reduction of platinum ions on a support is a relatively convenient way to fabricate nanoparticle based electrodes. There are some reports in the literature on the preparation of supported

\footnotetext{
*Corresponding authors: dulal_smsi@yahoo.com; ybshim@pusan.ac.kr
} 
platinum nanoparticles by electrochemical route [20-31]. The catalytic activity of the nanoparticles has also been tested. The catalytic performance of nanoparticles is crucially dependent on their size and shapes. The dispersion of the nanoparticles on the support has significant influence on the catalytic property. Monodispersed smaller particles with uniform size and distribution are normally desired for enhanced activity. Carbon materials such as powder, ink, cloth, paper, glassy carbon etc. are generally used as catalyst support. In the present work, platinum nanoparticles were grown on carbon felt by an electrochemical deposition method. Carbon felt was chosen because of its high surface area and it is commercially available. The characterization of the supported nanoparticles has been carried out by electrochemical technique and by scanning electron microscopy (SEM). The electrocatalytic property of the nanoparticles was tested by the oxidation of hydroquinone and phenol. These compounds are known as major organic pollutants in industrial waste and they are very difficult to treat in other conventional ways [32-40].

\section{Experimental}

Platinum nanoparticles were electrodeposited on carbon felt from $1 \mathrm{mM}$ aqueous solution of hydrogen hexachloroplatinate. Tri-sodium citrate was used a complexing agent and its concentration was $1 \mathrm{mM}$. Tri-sodium citrate was chosen because it was non-toxic and had brightening, levelling and buffering actions [41]. Moreover, citrate electrolyte was recently used for precision electrodeposition [42-46]. The solution was prepared by dissolving appropriate amount of the chemicals in de-ionised water. The chemicals used in this work were of analytical grade. Approximately $10 \mathrm{ml}$ solution was taken in a cell for electrodeposition of platinum nanoparticles. Commercially available carbon felt was used as substrate without any pre-treatment. The felt was cut to make rectangular electrode which had a length of approximately $4.0 \mathrm{~cm}$ and width of $0.7 \mathrm{~cm}$. The electrical contact was made with crocodile clip. Approximately $1 \mathrm{~cm}$ of the felt was immersed in the electrolyte for the deposition of nanoparticles and for subsequent electrochemical experiments.

An EG\&G (Model 273) potentiostat was used for the deposition of the nanoparticles and their electrochemical characterization. Platinum nanoparticles were deposited by potential cycling between 100 and $-500 \mathrm{mV}$ versus saturated $\mathrm{Ag} / \mathrm{AgCl}$ electrode. The scan rate was varied between 50 and $1500 \mathrm{mV} / \mathrm{s}$ and the cycle number was varied between 30 and 900. In all cases, the scanning was started and ended at $0 \mathrm{mV}$ versus a saturated $\mathrm{Ag} / \mathrm{AgCl}$ electrode. After the completion of the deposition of the nanoparticles, the felt electrode was washed with de-ionised water followed by ethanol and dried in oven at 100 ${ }^{\circ} \mathrm{C}$. The electrochemical characterization of the deposited platinum nanoparticles was performed by cyclic voltammetry in $1 \mathrm{M} \mathrm{H}_{2} \mathrm{SO}_{4}$. In this case, the potential was swept between -200 and $1500 \mathrm{mV}$ at the rate of $50 \mathrm{mV} / \mathrm{s}$.

For scanning electron microscopic examination of the deposited nanoparticles, several trends of the fibres were pulled out from the rectangular electrode with a tweezers and placed on a carbon tape pasted on the sample holder. To test the electrocatalytic activity of 
the platinum nanoparticles, various concentrations of hydroquinone (HQ) were used. The HQ concentration was varied between 1 and $10 \mathrm{mM}$. The HQ solution was prepared by dissolving appropriate amount of the reagent in aqueous solution of $1 \mathrm{M} \mathrm{H}_{2} \mathrm{SO}_{4}$. The electrooxidation of phenol at the nanoparticle based electrode was also tested. In this case, $5 \mathrm{mM}$ phenol in phosphate buffer $(\mathrm{pH} \mathrm{7})$ solution was used. For HQ degradation experiments, $10 \mathrm{ml}$ of $10 \mathrm{mM} \mathrm{HQ}$ solution (in $1 \mathrm{M} \mathrm{H}_{2} \mathrm{SO}_{4}$ ) was taken and performed cyclic voltammetry on a glassy carbon electrode. Then a platinum nanoparticle deposited felt electrode was immersed in the solution and a constant potential of $900 \mathrm{mV}$ was applied on the nanoparticle/felt electrode for a certain amount of time. Subsequently, cyclic voltammetry was performed using a glassy carbon electrode to see any change in the magnitude of the oxidation peak of HQ. This procedure was repeated several times on the same electrolyte.

\section{Results and Discussion}

\subsection{Electrodeposition of platinum nanoparticles}

The platinum nanoparticles were electrodeposited on carbon felt by potential cycling between 100 and $-500 \mathrm{mV}$ from an aqueous electrolyte containing $1 \mathrm{mM}$ hydrogen hexachloroplatinate and $1 \mathrm{mM}$ tri-sodium citrate. The cyclic voltammograms are shown in Fig. 1 . In this case, the scan rate was $50 \mathrm{mV} / \mathrm{s}$ and the number of cycle was 30. It can be seen from the figure that the deposition current was increase with increasing number of cycle. This is possibly due to the creation of some new nucleation sites in the subsequent cycles or hydrogen evolution on the already deposited platinum nanoparticles.

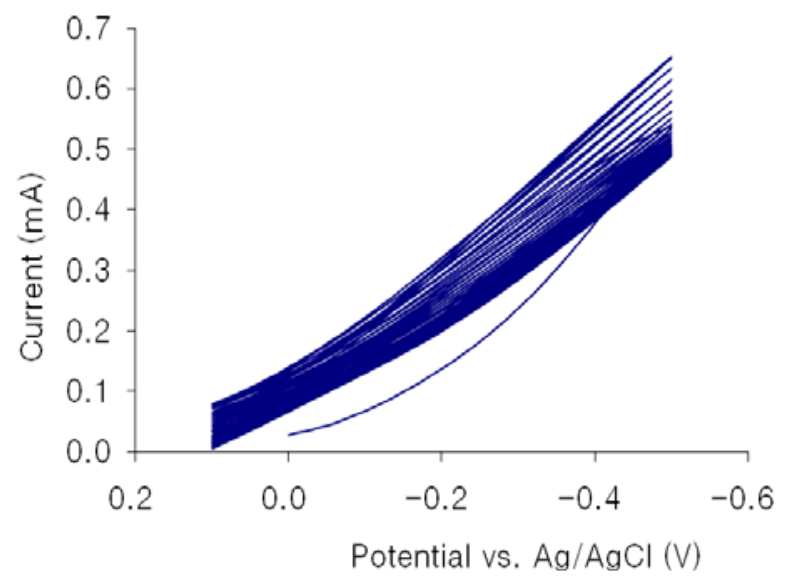

Fig. 1. Typical cyclic voltammograms for the deposition of platinum nanoparticles on carbon felt. The electrolyte contained $1 \mathrm{mM}$ sodium hexachloroplatinate and $1 \mathrm{mM}$ tri-sodium citrate. The scan rate was $50 \mathrm{mV} / \mathrm{s}$ and the number of cycle was 30 . 


\subsection{Characterisation of the deposited nanoparticles}

As shown in Fig. 2, the electrochemical characterization of the deposited platinum nanoparticle/felt electrode was carried out by potential cycling in $1 \mathrm{M} \mathrm{H}_{2} \mathrm{SO}_{4}$. Curve 'a' in Fig. 2 shows a typical polarization curve of an aqueous solution containing $1 \mathrm{M} \mathrm{H}_{2} \mathrm{SO}_{4}$ at a platinum coil electrode. Curve 'b' and 'c' show voltammograms at a bare felt electrode and platinum nanoparticle deposited felt electrode, respectively, in $1 \mathrm{M} \mathrm{H}_{2} \mathrm{SO}_{4}$. As seen in the figure, curve 'c' exhibits the characteristic peaks of those of pure platinum. This suggests the existence of platinum on the carbon felt.

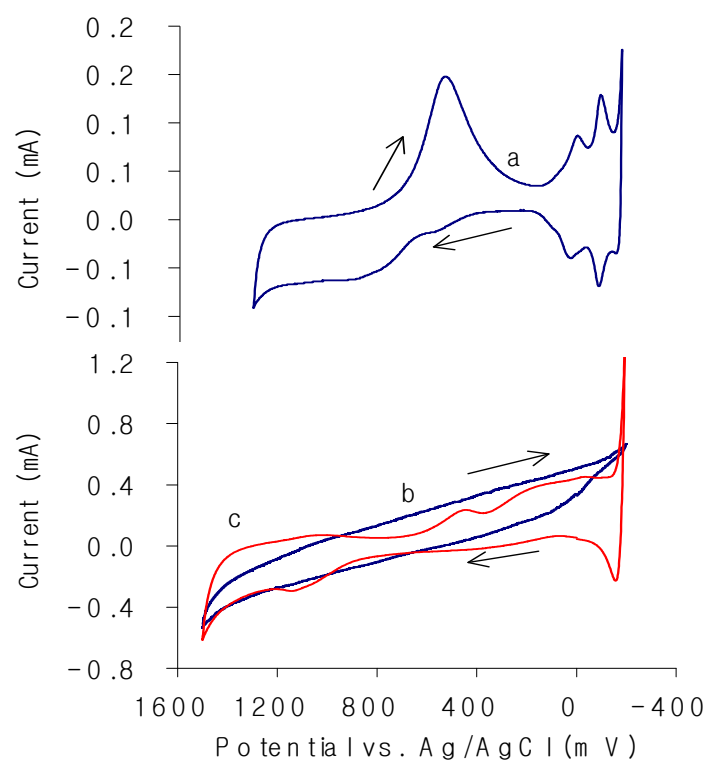

Fig. 2. Cyclic voltammograms of (a) platinum wire, (b) carbon felt and (c) platinum nanoparticle deposited carbon felt in $1 \mathrm{M} \mathrm{H}_{2} \mathrm{SO}_{4}$; scan rate was $50 \mathrm{mV} / \mathrm{s}$. Platinum nanoparticles were deposited on carbon felt by potential cycling between 100 and $-500 \mathrm{mV}$ at the rate of $50 \mathrm{mV} / \mathrm{s}$ and the number of cycle was 30 .

The electrochemical characterization provides no information about the shape and size of the deposited platinum. Therefore, SEM image of the platinum deposited felt was taken. Fig. 3 shows SEM micrographs of three samples prepared under three different electrochemical parameters. The corresponding deposition parameters of images ' $a$ ', ' $b$ ' and 'c' were given in the figure captions. It can be seen in Fig. 3 that the particle size decreases with increasing scan rate. Average diameter of the particles obtained at a scan rate of $50 \mathrm{mV} / \mathrm{s}$ is approximately $200 \mathrm{~nm}$ (Fig. 3a). On the other hand, average diameter of the particles prepared at $1500 \mathrm{mV} / \mathrm{s}$ is approximately $50 \mathrm{~nm}$ (Fig. 3c). A better particle distribution with an average diameter of $60 \mathrm{~nm}$ was observed when they were deposited at a scan rate of $800 \mathrm{mV} / \mathrm{s}$ (Fig. 3b). 


\subsection{Catalytic property of supported platinum nanoparticles}

The catalytic activity of the carbon felt supported platinum nanoparticles was tested by the electrooxidation of hydroquinone and phenol. These compounds are chosen because they are considered as major organic pollutants in industrial wastewater, which have been found very difficult for treatment in other conventional ways. Fig. 4 shows cyclic voltammograms of a solution containing various concentrations of $\mathrm{HQ}$ in $1 \mathrm{M} \mathrm{H}_{2} \mathrm{SO}_{4}$ at the felt supported platinum nanoparticle electrode. It can be seen in the figure that the redox reaction occurs at the electrode and the currents (both oxidation and reduction) increase with increasing concentration of hydroquinone.
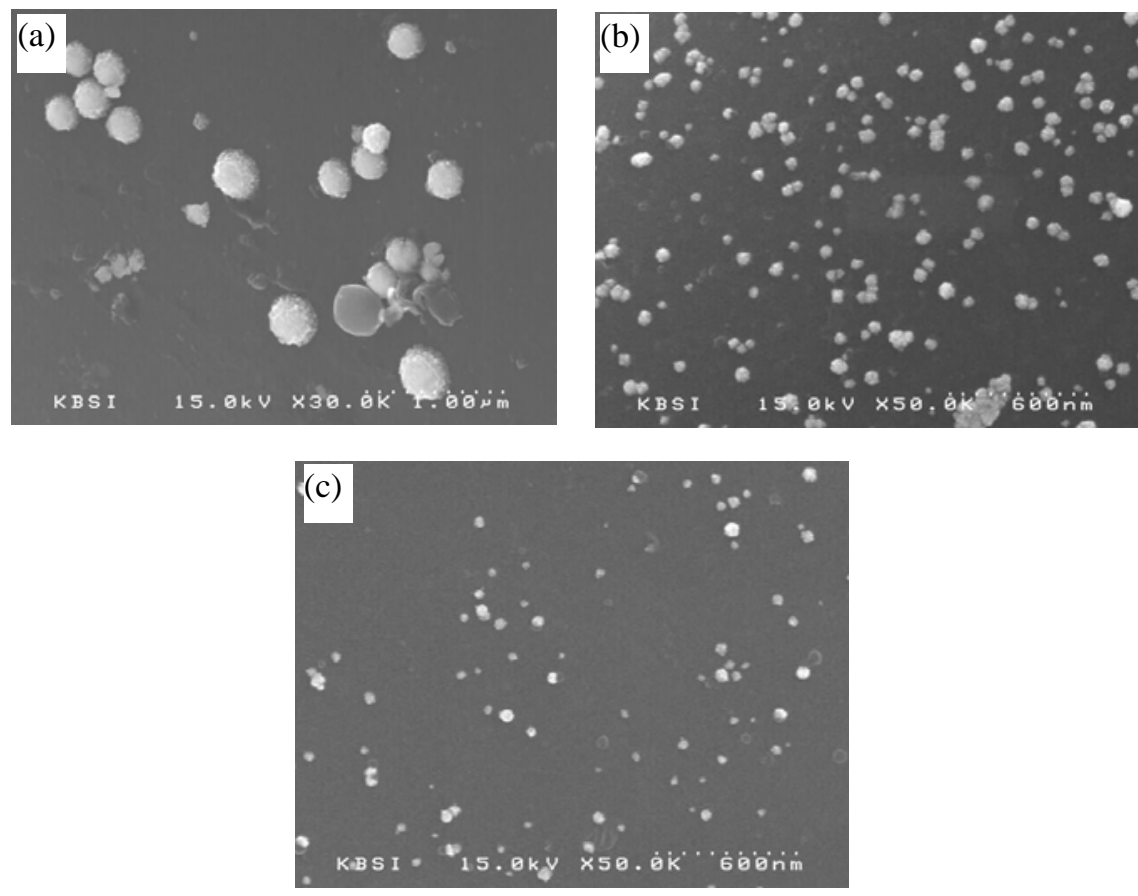

Fig. 3. SEM micrographs of platinum nanoparticles deposited on carbon felt at various scan rates and cycles. (a) scan rate was $50 \mathrm{mV} / \mathrm{s}$, number of cycle was 30 and average diameter of the nanoparticles was $280 \mathrm{~nm}$, (b) scan rate was $800 \mathrm{mV} / \mathrm{s}$, number of cycle was 430 and average diameter of the nanoparticles was $60 \mathrm{~nm}$, and (c) scan rate was $1500 \mathrm{mV} / \mathrm{s}$, number of cycle was 900 and average diameter of the nanoparticles was $55 \mathrm{~nm}$.

The degradation of HQ on the nanoparticle/felt electrode was carried out by applying a constant potential of $900 \mathrm{mV}$ on the electrode immersed in HQ solution and performing cyclic voltammetry using a glassy carbon electrode after a regular interval of time. It was visually observed that the colour of the HQ solution started to change into reddish-yellow 10 minute after the application of the potential on the nanoparticle/felt electrode. The 
voltammograms of the degrading HQ solution at glassy carbon electrode in several intervals of time are shown in Fig. 5. The figure shows that the oxidation peak of the HQ solution decreased with increasing time of applied potential on the nanoparticle/felt electrode. Although the extent of decrease of the oxidation peak of HQ with time is very slow, it provides information about the effectiveness of such electrodes for the degradation of HQ.

Fig. 6 shows polarization curve of an aqueous phosphate buffer (pH 7) solution containing $5 \mathrm{mM}$ phenol. The curve shows a clear oxidation wave of phenol electrooxidation. It has been found that the peak current for phenol oxidation decreased drastically in the subsequent cycle. In the case of phenol electrooxidation, the electrode fouling by sort of polymeric products is a well know phenomenon.
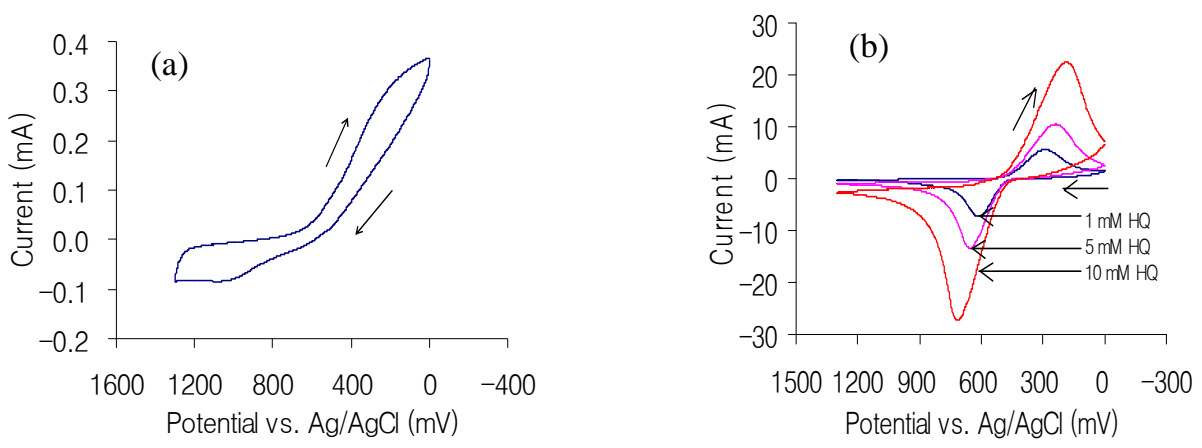

Fig. 4. (a) Cyclic voltammogram of $5 \mathrm{mM}$ hydroquinone (HQ) in $1 \mathrm{M} \mathrm{H}_{2} \mathrm{SO}_{4}$ at bare felt electrode (no deposited platinum nanoparticle on the felt). (b) Cyclic voltammograms of solutions containing various concentrations of $\mathrm{HQ}$ in $1 \mathrm{M} \mathrm{H}_{2} \mathrm{SO}_{4}$ at platinum nanoparticle containing carbon felt working electrode. The nanoparticles were deposited from $1 \mathrm{mM}$ Pt solution by potential cycling between 100 and $-500 \mathrm{mV}$ at a rate of $50 \mathrm{mV} / \mathrm{s}$ and number of cycle was 30 .

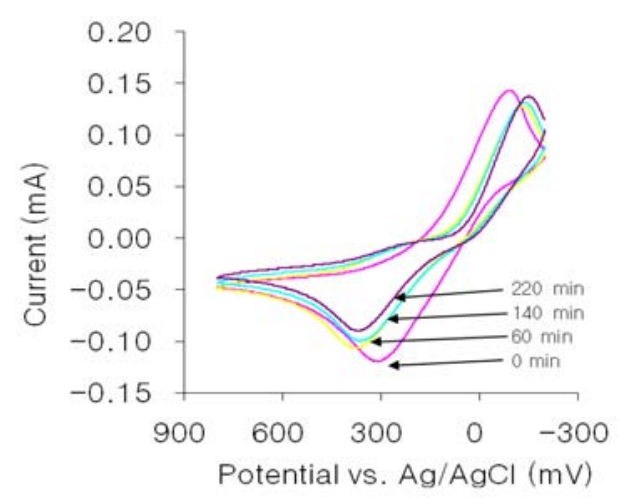

Fig. 5. Cyclic voltammograms of a solution containing $10 \mathrm{mM} \mathrm{HQ}$ in $1 \mathrm{M}_{2} \mathrm{SO}_{4}$ at a glassy carbon electrode after a regular interval of time. The solution was being oxidized simultaneously on the felt supported platinum nanoparticle electrode at a constant potential of $900 \mathrm{mV}$. 


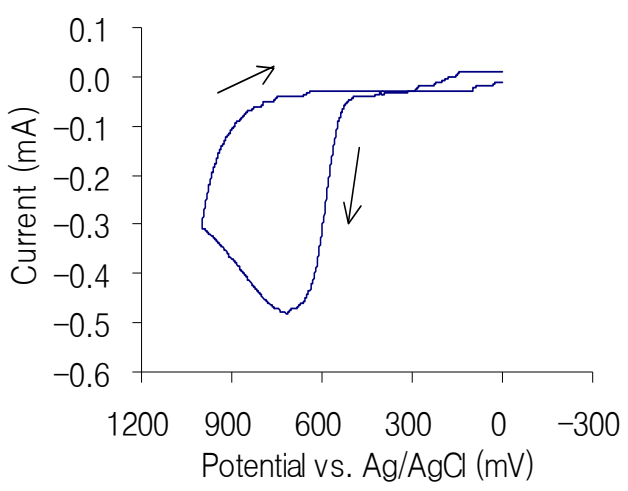

Fig. 6. A cyclic voltammogram of $5 \mathrm{mM}$ phenol in phosphate buffer $(\mathrm{pH}$ 7) solution. The potential was swept at the rate of $50 \mathrm{mV} / \mathrm{s}$. The working electrode was platinum nanoparticles deposited on felt by potential cycling between 100 and $-500 \mathrm{mV}$ at the rate of $50 \mathrm{mV} / \mathrm{s}$ and the total number of cycle was 30.

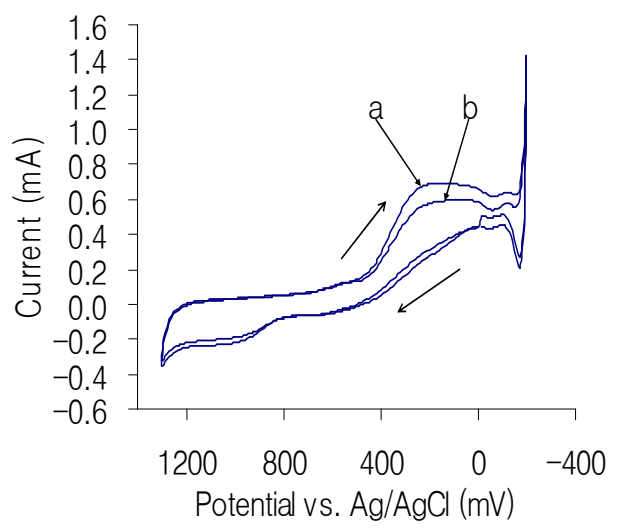

Fig. 7. Cyclic voltammograms at a platinum nanoparticle deposited felt in a $1 \mathrm{M} \mathrm{H}_{2} \mathrm{SO}_{4}$ for 1 hour; scan rate was $50 \mathrm{mV} / \mathrm{s}$ and number of cycle was 60 , (a) the first cycle and (b) the last cycle.

\subsection{Stability of the deposited nanoparticles}

The stability of the plated nanoparticles on the surface of carbon felts was also tested. This experiment was carried out by consecutive cycling at the nanoparticle/felt electrode in $\mathrm{H}_{2} \mathrm{SO}_{4}$ and in hydroquinone. Fig. 7 shows voltammograms in $1 \mathrm{M} \mathrm{H}_{2} \mathrm{SO}_{4}$ at the platinum nanoparticle/felt electrode. There were 60 cycles at the rate $50 \mathrm{mV} / \mathrm{s}$ in the range between -200 and $1300 \mathrm{mV}$. Hence the potential cycling time was 1 hour. Curve 'a' in Fig. 7 is of the first cycle and curve ' $b$ ' is of the last cycle. The figure shows the characteristic polarization curves at platinum electrode (Fig. 2) even after one hour's of cycling in sulphuric acid. This suggests the existence of the nanoparticles on the carbon felt, i.e., the stability of nanoparticles on the felt. The figure also shows that the redox currents for the 
oxide layer on the platinum surface decrease slightly with increasing number of cycles. However, these currents were found to attain at the level of the first cycle when a second potential sweeping experiment was started.

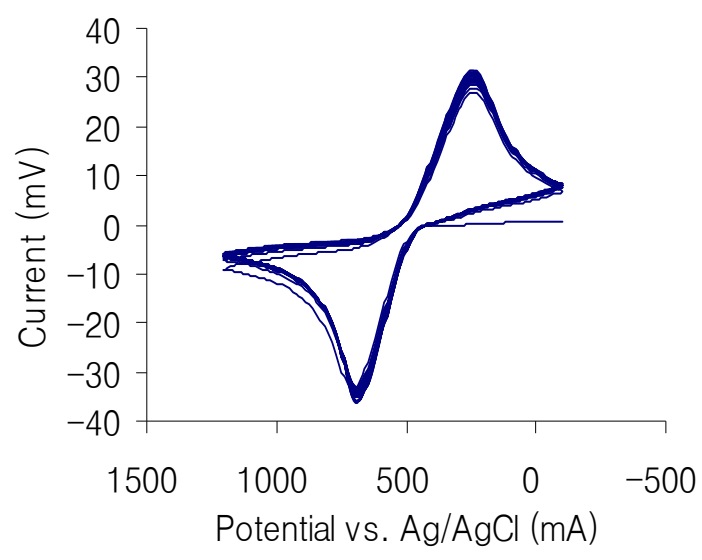

Fig. 8. Consecutive cyclic voltammograms (20 cycles) of $10 \mathrm{mM}$ hydroquinone in $1 \mathrm{M} \mathrm{H}_{2} \mathrm{SO}_{4}$ using a platinum deposited felt working electrode. Platinum nanoparticles were deposited from $1 \mathrm{mM} \mathrm{Pt}$ solution by potential cycling between 100 and $-500 \mathrm{mV}$ at the rate of $800 \mathrm{mV} / \mathrm{s}, 430$ cycles.

Fig. 8 shows consecutive cyclic voltammograms of $10 \mathrm{mM}$ hydroquinone in $1 \mathrm{M}$ $\mathrm{H}_{2} \mathrm{SO}_{4}$ solution at a platinum nanoparticle deposited felt electrode. There is a little decrease in the redox current with increasing number of cycle. This may be due to the change of the surface of the electrode but certainly not due to the loosing of the nanoparticles from the carbon felt. This experiment suggests that the platinum nanoparticles are very stable on the carbon felt when used them as electrodes for oxidation of phenolic compounds like hydroquinone.

\section{Conclusions}

Platinum nanoparticles were electrodeposited on carbon felt from an aqueous electrolyte containing hydrogen hexachloroplatinate by a potential cycling method. The felt supported nanoparticles were characterized by electrochemical means and by scanning electron microscopy. It was found that the particle size and distribution on the support were strongly dependant on scan rate. Monodispersed and evenly distributed nanoparticles were deposited at relatively higher scan rates. The size of the nanoparticles decreased with increase in scan rate. It was also found experimentally that the nanoparticles were very stable and strongly adherent to the felt support. Catalytic activity of the nanoparticles was tested by the oxidation of hydroquinone and phenol. Much higher oxidation current was found when carbon felt was reinforced with platinum nanoparticles. Therefore, there was 
a bright prospect for the use of carbon felt supported platinum nanoparticles for industrial waste treatment.

\section{Acknowledgements}

At the time the research was conducted, S. M. S. I. Dulal was in the Department of Chemistry, Pusan National University, as a postdoctoral research fellow. The work was supported by the Basic Science Research Program through the National Research Foundation funded by the Ministry of Education, Science and Technology (Grant No. 20090079376), South Korea.

\section{References}

1. K. -Y. Chan, J. Ding, J. Ren, S. Cheng, and K. Y. Tsang, J. Mater. Chem. 14, 505 (2004). doi:10.1039/b314224h

2. E. Antolini, Mater. Chem. Phys. 78, 563 (2003). doi:10.1016/S0254-0584(02)00389-9

3. D. A. Stevens and J. R. Dahn, J. Electrochem. Soc. 150, A770 (2003). doi:10.1149/1.1573195

4. D. -Q. Yang and E. Sacher, Chem. Mater. 18, 1811 (2006). doi:10.1021/cm052453e

5. Z. Wu, L. Chen, G. Shen, and R. Yu, Sensors Actuators B 119, 295 (2006). doi:10.1016/j.snb.2005.12.023

6. J. Wang, Analyst, 130, 421 (2005). doi:10.1039/b414248a

7. S. Wang and X. Lin, Electrochim. Acta 50, 2887 (2005). doi:10.1016/j.electacta.2004.11.037

8. H. Tang, J. Chen, S. Yao, L. Nie, G. Deng, and Y. Kuang, Anal. Biochem. 331, 89 (2004).

9. T. You, O. Niwa, M. Tomita, and S. Hirono, Anal. Chem. 75, 2080 (2003). doi:10.1021/ac026337w

10. J. Luo, M. M. Maye, V. Petkov, N. N. Kariuki, L. Wang, P. Njoki, D. Mott, Y. Lin, and C. -J. Zhong, Chem. Mater. 17, 3086 (2005). doi:10.1021/cm050052t

11. G. Yu, W. Chen, J. Zhao, and Q. Nie, J. Appl. Electrochem. 36, 1021 (2006). doi:10.1007/s10800-006-9163-6

12. M. -S. Loffler, B. Grob, H. Natter, R. Hempelmann, Th. Krajewski, and J. Divisek, Phys. Chem. Chem. Phys. 3, 333 (2001). doi:10.1039/b005055p

13. M. S. Nashner, A. I. Frenkel, D. L. Adler, J. R. Shapley, and R. G. Nuzzo, J. Am. Chem. Soc. 119, 7760 (1997). doi:10.1021/ja971039f

14. H. Tang, J. Chen, S. Yao, L. Nie, Y. Kuang, Z. Huang, D. Wang, and Z. Ren, Mater. Chem. Phys. 92, 548 (2005). doi:10.1016/j.matchemphys.2005.02.009

15. T. M. Day, P. R. Unwin, N. R. Wilson, and J. V. Macpherson, J. Am. Chem. Soc. 127, 10639 (2005). doi:10.1021/ja051320r

16. J. M. Sieben, M. M. E. Duarte, C. E. Mayer, and J. C. Bazán, J. Appl. Electrochem. 39, 1045 (2009). doi:10.1007/s10800-008-9756-3

17. S. Dominguez-Dominguez, J. Arias-Pardilla, A. Berenguer-Murcia, E. Morallon, and D. Cazorla-Amoros, J. Appl. Electrochem. 38, 259 (2008). doi:10.1007/s10800-007-9435-9

18. M. M. E. Duarte, A. S. Pilla, J. M. Sieben, and C. E. Mayer, Electrochem. Commun. 8, 159 (2006). doi:10.1016/j.elecom.2005.11.003

19. S. M. S. I. Dulal, M. -S. Won, and Y. -B. Shim, J. Alloys Compd. 494, 463 (2010). doi:10.1016/j.jallcom.2010.01.083

20. X. Dai and R. G. Compton, Analyst 131, 516 (2006). doi:10.1039/b513686e

21. J. -S. Ye, H. -F. Cui, Y. Wen, W. D. Zhang, G. Q. Xu, and F. -S. Sheu, Microchim. Acta 152, 267 (2006). doi:10.1007/s00604-005-0446-0

22. F. Gloaguen, J. -M. Leager, and C. Lamy, J. Appl. Electrochem. 27, 1052 (1997). 
doi:10.1023/A:1018434609543

23. M. Chikae, K. Idegami, K. Kerman, N. Nagatani, M. Ishikawa, Y. Takamura, and E. Tamiya, Electrochem. Commun. 8, 1375 (2006). doi:10.1016/j.elecom.2006.06.019

24. K. H. Choi, H. S. Kim, and T. H. Lee, J. Power Sources 75, 230 (1998). doi:10.1016/S0378-7753(98)00116-5

25. H. -F. Cui, J. -S. Ye, W. -D. Zhang, J. Wang, and F. -S. Sheu, J. Electroanal. Chem. 577, 295 (2005). doi:10.1016/j.jelechem.2004.12.004

26. M. M. Waje, X. Wang, W. Li, and Y. Yan, Nanotechnology 16, S395 (2005). doi:10.1088/0957-4484/16/7/013

27. G. Lu and G. Zangari, J. Phys. Chem. B 109, 7998 (2005). doi:10.1021/jp0407324

28. R. S. Jayashree, J. S. Spendelow, J. Yeom, C. Rastogi, M. A. Shannon, and P. J. A. Kenis, Electrochim. Acta 50, 4674 (2005). doi:10.1016/j.electacta.2005.02.018

29. R. G. Allen, C. Lim, L. X. Yang, K. Scott, and S. Roy, J. Power Sources 143, 142 (2005). doi:10.1016/j.jpowsour.2004.11.038

30. J. V. Zoval, J. Lee, S. Gorer, and R. M. Penner, J. Phys. Chem. B 102, 1166 (1998). doi:10.1021/jp9731967

31. J. -H. Yoon, G. Muthuraman, J. E. Yang, Y. -B. Shim, and M. -S. Won, Electroanalysis 19, 1160 (2007). doi:10.1002/elan.200703835

32. C. H. Tzang, C. -W. Li, J. Zhao, and M. Yang, Anal. Letters 38, 1735 (2005). doi:10.1080/00032710500207879

33. J. -H. Yoon, E. D. Jeong, Y. -B. Shim, and M. -S. Won, Key Eng. Mater. 277-279, 445 (2005). doi:10.4028/www.scientific.net/KEM.277-279.445

34. D. Fino, C. C. Jara, G. Saracco, V. Specchia, and P. Spinellij, J. Appl. Electrochem. 35, 405 (2005). doi:10.1007/s10800-005-0799-4

35. S. Cao, G. Chen, X. Hu, and P. L. Yue, Catal. Today 88, 37 (2003). doi:10.1016/j.cattod.2003.08.005

36. S. Andreescu, D. Andreescu, and O. A. Sadik, Electrochem. Commun. 5, 681 (2003). doi:10.1016/S1388-2481(03)00166-8

37. R. A. Torres, W. Torres, P. Peringer, and C. Pulgarin, Chemosphere 50, 97 (2003). doi:10.1016/S0045-6535(02)00487-3

38. S. Tanaka, Y. Nakata, T. Kimura, Yustiawati, M. Kawasaki, and H. Kuramitz, J. Appl. Electrochem. 32, 197 (2002). doi:10.1023/A:1014762511528

39. J. D. Rodgers, W. Jedral, and N. J. Bunce, Environ. Sci. Technol. 33, 1453 (1999). doi:10.1021/es9808189

40. J. -L Boudenne, O. Cerclier, and P. Bianco, J. Electrochem. Soc. 145, 2763 (1998). doi:10.1149/1.1838711

41. S. M. S. I. Dulal, The Electrochemical and Physical Properties of Nanostructured Magnetic Multilayers, PhD thesis, University of Newcastle upon Tyne, UK (2003).

42. S. M. S. I. Dulal, E. A. Charles, and S. Roy, Electrochim. Acta 49, 2041 (2004). doi:10.1016/j.electacta.2003.12.038

43. S. M. S. I. Dulal, E. A. Charles, and S. Roy, J. Appl. Electrochem. 34, 151 (2004). doi:10.1023/B:JACH.0000009945.92160.25

44. S. M. S. I. Dulal and E. A. Charles, J. Alloys Compd. 455, 274 (2008).

45. S. M. S. I. Dulal and E. A. Charles, Trans. Inst. Met. Finish. 86, 260 (2008). doi:10.1179/174591908X345013

46. S. M. S. I. Dulal and E. A. Charles, J. Phys. Chem. Solids 71, 309 (2010). doi:10.1016/j.jpcs.2009.12.082 